\title{
Hypertension During Pregnancy: A Link to Post-Partum Depression and Anxiety?
}

\author{
Kedra Wallace ${ }^{1,2 *}$ and Shauna-Kay Spencer ${ }^{1}$ \\ ${ }^{1}$ Department of Obstetrics \& Gynecology, University of Mississippi Medical Center, USA \\ ${ }^{2}$ Department of Neurobiology and Anatomical Sciences; University of Mississippi Medical Center, USA
}

Submission: April 05, 2018; Published: July 26, 2018

*Corresponding author: Kedra Wallace, Department of Obstetrics \& Gynecology, University of Mississippi Medical Center, 2500 North State St., Jackson, MS39216, USA, Tel: (0) 601-984-5396; Email: kwallace2@umc.edu

Abstract

Hypertension during pregnancy is a common occurrence affecting 3-10\% of pregnancies, while depression and anxiety in different stages of pregnancy are at a higher yield with almost $30-70 \%$ of women reporting depressive like symptoms. This mini review seeks to explore the correlation between hypertensive disorders during pregnancy such as preeclampsia and HELLP syndrome and prevalence of postpartum depression (PPD) or postpartum anxiety (PPA). Studies show women with PPD and or PPA with a history of Preeclampsia, HELLP or Normal pregnancies have no statistical differences. The review of literature identifies a clear lack of prospective trials. This is a limiting factor that could lead to the misrepresentation of statistical differences. Also the way these women are evaluated further compounds the problem in that only three recognized instruments are designed to assess PPD while several studies use the self-report and recall test which yields less than accurate results. Systemic inflammation is common in depression and anxiety in both sexes is also prevalent in pregnant women with hypertension, also suggesting a correlation. Neuroinflammation has been shown to cause cerebral autoregulation dysfunction which may cause disruption of the blood-brain barrier leading to temporary or permanent neurological changes. These neuronal changes could be the cause of depression and anxiety in pregnancy. While there is currently no definitive association between hypertensive disorders, PPD and PPA the same underlying factors that cause neuronal damages and neuroinflammation are common between all three conditions.

Keywords: Anxiety; Blood-brain barrier; Hypertension; Inflammation Post-partum depression; Pregnancy

Abbreviations: BBB: Blood Brain Barrier; HELLP: Hemolysis Elevated Liver Enzyme and Low Platelets; PPA: Post-Partum Anxiety; PPD: PostPartum Depression; PreE: Preeclampsia; PTSD: Post-traumatic Stress Disorder

\section{Introduction}

Depression during the childbearing years is the 2nd leading cause of disability among women with an increased risk during the perinatal period $[1,2]$. During the prenatal period almost $70 \%$ of women have reported symptoms of depression during pregnancy $[3,4]$ while $10-43 \%$ of women meet the criteria for depression $[5,6]$. Stress and anxiety are also often linked to depression especially in the postpartum period and is thought to affect between $5-20 \%$ of women $[7,8]$. Hypertension affects $3-10 \%$ of pregnancies $[9,10]$ and is most commonly manifested as either preeclampsia (PreE) or HELLP (Hemolysis Elevated Liver enzyme Low Platelet) syndrome. HELLP occurs in 10-20\% of women with PreE and in $0.5 \%$ of women without PreE [1113].

\section{Discussion}

Hypertensive pregnancies and post-partum depression and post-partum anxiety

Hypertensive disorders during pregnancy are associated with adverse birth outcomes, many of which have been found to be associated with perinatal depression. As described in a metaanalysis by Grote et al [14] preterm birth and low birth weight were found to be significantly associated with depression in some of the studies examined. Despite these associations, studies have reported conflicting data as to whether women with a history of high risk pregnancies such as PreE and HELLP syndrome experience PPD or PPA. If the mental health disturbances they experience are due to their maternal disorders or with having 
babies admitted to the neonatal intensive care unit or possibly who have died [15].

A systematic review by Delahaije et al discusses the findings from six studies (4 retrospective and 2 prospective) which examined the prevalence of PPD and PPA (either anxiety or posttraumatic stress disorder; PTSD) in women with a history of PreE, HELLP vs women with normal pregnancies [16]. They concluded that there was not a clear statistical indication of PPD among women with PreE and HELLP despite positive associations with depressive symptoms. However, similar to what Grote et al reported there is a clear relationship between depression and having a preterm vs term baby. Having a pregnancy complicated by either PreE or HELLP syndrome was statistically associated with PTSD and while women with a PreE pregnancy had more traits for anxiety it was not statistically significant compared to normal pregnant women.

One of the more pressing problems with identifying a relationship between hypertensive pregnancies and PPD/PPA is the lack of prospective clinical trials. Currently there are 5 trials listed in clinical trials.gov that have hypertension as a direct or indirect factor associated with PPD and/or PPA and fewer have been published. Adding to this conundrum are the mixed survey instruments that are performed across retrospective and prospective studies. The Bromley Postnatal Depression Scale, Edinburgh Postnatal Depression Scale and the Postpartum Depression Screening Scale are the only three instruments that are designed to assess PPD [17]. However, several studies have used self-report and recall to assess PPD or PPA which can yield less than accurate results.

\section{Inflammation,hypertensive pregnancieanddepression and anxiety}

Systemic inflammation has long been associated with major depression and with anxiety in both men and women $[18,19]$. Inflammation has also been associated with the progression of symptoms and in contributing to hypertension in both PreE and HELLP syndrome [20-22]. Additionally during pregnancy the brain is particularly susceptible to inflammatory changes in the peripheral circulation which may make it vulnerable to neuroinflammation. While the exact etiology of HELLP and PreE remain unknown, they are most commonly thought to originate from abnormal remodeling of the uterine spiral arteries, which creates an ischemic placenta that secretes and stimulates factors leading to the pathophysiology of these disorders $[23,24]$. The neurological symptoms include headaches and visual impairments and upon neuroimaging can include evidence of white matter lesions, hemorrhage and cerebral edema [25-29].

One mechanism thought to play a role in the development of these neurological complications is impaired cerebral autoregulation [30,31]. Cerebral autoregulation is a vital physiologic process that allows the maintenance of cerebral perfusion pressure despite fluctuations in blood pressure, maintained in part by vasoconstriction and vasodilation of cerebral vessels [30-32]. The BBB is a highly complex neurological structure that plays a crucial role in maintaining neuronal homeostasis and cerebral autoregulation [33]. Disruption of the BBB may allow for the transfer of harmful chemicals into the brain and negatively affect neuronal homeostasis and its disruptied BBB can be detrimental to the CNS leading to temporary or permanent neurological changes.

Interestingly, BBB disruption has been implicated in the hypertensive disorders of pregnancy [33-35]. Disruption in women with hypertensive disorders of pregnancy suffer not only immediate consequences from this disorder but also long term sequelae [36], thereby highlighting the importance of BBB disruption and ultimately these neurological events. The exact underlying mechanisms causing BBB dysfunction seen in women with PreE and HELLP remain unknown; however, the acute hypertension and peripheral inflammation either alone or in combination is thought to alter BBB permeability and contribute to the varying neurological complications [37-39]. It is also well established in both human and animal studies that circulating factors, potentially inflammatory factors, in subjects with PE or HELLP syndrome contribute to BBB disruption and neuroinflammation $[20,34,35,39,40]$. Therefore one could postulate that the increase in BBB permeability or decrease in $\mathrm{BBB}$ function could contribute to changes in the neural environment during pregnancy or the immediate post-partum period.

\section{Conclusion}

In conclusion, as untreated and unrecognized perinatal depression is still one of the best predictors for PPD and/or PPA it is important for women and their health providers to discuss mental health during their prenatal care and post-partum care [41]. Additionally, as pharmacologic therapy, primarily antidepressants, during pregnancy have been associated with an increased risk for preterm birth and low birth weight as well as potentially developmental problems in the offspring it is important to understand some of the mechanisms that might contribute to PPD and/or PPA $[42,43]$. The data thus far only allows for us to make a causal association regarding the likelihood women with PreE or HELLP syndrome develop PPD and/or PPA. It is also recommended that future prospective studies utilize one of the three approved post-partum instruments to help with future translation.728)

\section{References}

1. O’Hara M, McCabe J (2013) Postpartum depression: current status and future directions. Annu Rev Clin Psychol 9: 379-407.

2. Organization WH (2001) The World Health Report: The world health report 2001 - Mental Health: New Understanding, New Hope, USA.

3. Committee A (2008) ACOG Practice Bulletin: Clinical management guidelines for obstetrician-gynecologists number 92, April 2008 (replaces practice bulletin number 87, November 2007): use of 
psychiatric medications during pregnancy and lactation. Obstet and Gynecology 111(4): 1001-1020.

4. Yonkers K, Wisner K, Stewart DE, Oberlander TF, Dell DL, et al. (2009) The management of depression during pregnancy: A report from the American Psychiatric Association and the American College of Obstetricians and Gynecologists. Gen Hosp Psychiatry 31(5): 403-413.

5. O'Hara M, Swain A (1996) Rates and risks of post-partum depression-A meta-analysis. Int Rev Psychiatry 8(1): 37-54.

6. Gavin N, Gaynes B, Lohr K, Meltzer-Brody S, Gartlehner G, et al. (2005) Perinatal depression: a systematic review of prevalence and incidence. Obstet Gynecol 106(5pt1): 1071-1083.

7. Miller R, Pallant J, Negri L (2006) Anxiety and stress in the postpartum: Is there more to postnatal distress than depression? BMC Psychiatry 6: 12 .

8. Ross L, McLean L (2006) Anxiety disorders during pregnancy and the postpartum period: A systematic review. J Clin Psychiatry 67(8): 12851298.

9. Magee L, Pels A, Helewa M, Rey E, Dadelszen VP, et al. (2015) The hypertensive disorders of pregnancy (29.3). Best Pract Res Clin Obstet Gynaecol 29(5): 643-657.

10. Mogos M, Salemi J, Spooner K, McFarin B, Salihu H, et al. (2017) Hypertensive disorders of pregnancy and postpartum readmission in the United States: national surveillance of the revolving door. J Hypertension 36(3): 608-618.

11. Geary M (1997) The HELLP syndrome. British Journal of Obstetrics and Gynaecology 104(8): 887-891.

12. Sibai B (2004) Diagnosis, controversies, and management of the syndrome of hemolysis, elevated liver enzymes and low platelet count. Obstet Gynecol 103(5 pt 1): 981-991.

13. Abildgaard U, Heimdal K (2013) Pathogenesis of the syndrome of hemolysis, elevated liver enzymes, and low platelet count (HELLP): review. Eur J Obstet Gynecol Reprod Biol 166(2): 117-123.

14. Grote N, Bridge J, Gavin A, Melville J, Iyengar S, et al. (2010) A Metaanalysis of depression during pregnancy and the risk of pre-term birth low birth weight and intrauterine growth restriction. JAMA Psychiatry 67(10): 1012-1024.

15. Hoedjes M, Berks D, vogel I, Franx A, Bangma M, et al. (2011) Postpartum depression after mild and severe preeclampsia. J Womens Health 20(10): 1535-1542.

16. Delahaije D, Dirksen C, Peeters L, Smits L (2013) Anxiety and depression following preeclampsia or HELLP syndrome. A systematic review. Acta Obstet Gynecol Scand 92(7): 746-761.

17. Mitchell A, Coyne J (2010) Screening for depression in clinical practice. An evidence-based guideline. Oxford: Oxford University Press, USA 20(4): 447-448.

18. Miller A, Maletic V, Raison C (2009) Inflammation and its discontents: the role of cytokines in the pathophysiology of major depression. Biol Psychiatry 65(9): 732-741.

19. Vogelzangs N, Beekman A, Jonge DP, Penninx B (2013) Anxiety disorders and inflammation in a large adult cohort. Transl Psychiatry 3: e249.

20. Bean C, Spencer S, Bowles T, Kyle PB, Williams JM et al. (2016) Inhibition of $\mathrm{T}$ cell-activation attenuates hypertension, TNF-alpha, IL-17 and blood-brain barrier permeability in pregnant rats with angiogenic imbalance. Am J Reprod Immunol 76(4): 272-279.

21. Lamarca B, Cornelius D, Wallace K (2013) Elucidating Immune Mechanisms Causing Hypertension During Pregnancy. Physiology 28(4): 225-233.
22. Wallace K, Martin J, Tam TK (2013) Seeking the Mechanisms of Action for Corticosteroids in HELLP Syndrome: SMASH Study. Am J Obstet Gynecol 208(5): e1-e8.

23. Haram K, Svendsen E, Abildgaard U (2009) The HELLP syndrome: Clinical issues and management. A Review. BMC Pregnancy and Childbirth 9: 8.

24. Naderi S, Tsai S, Khandelwal A (2017) Hypertensive disorders of pregnancy. Curr Atheroscler Rep 19(3): 15.

25. Siepmann T, Boardman H, Bilderbeck A, Griffanti L, Kenworthy Y, et al. (2017) Long-term cerebral white and gray matter changes after preeclampsia. Neurology 88(13): 1256-1264.

26. Loureiro R, Leite C, Kahhale S, Freire S, Sousa B, et al. (2003) Diffusion imaging may predict reversible brain lesions in eclampsia and severe preeclampsia: initial experience. Am J Obstet Gynecol 189(5): 13501355 .

27. Wiegman M, Zeeman G, Aukes A, Faas M, Aarnoudse J, et al. (2014) Regional distribution of cerebral white matter lesions years after preeclampsia and eclampsia. Obstet Gynecol 123(4): 790-795.

28. Aukes A, Groot DJ, Wiegman M, Aarnoudse J, Sanwikarja G, et al. (2012) Long-term cerebral imaging after pre-eclampsia. BJOG 119(9): 11171122.

29. Paul B, Juneja S, Paul G, Gupta S (2013) Spectrum of neurological complications in HELLP syndrome. Neurol India 61(5): 467-471.

30. Veen VT, Panera R, Haeri S, Griffioen A, Zeeman G, et al. (2013) Cerebral autoregulation in normal pregnancy and preeclampsia. Obstet Gynecol 122(5): 1064-1069.

31. Veen VT, Panerai R, Haeri S, Berg VDP, Zeeman G, et al. (2016) Changes in cerebral autoregulation in the second half of pregnancy and compared to non-pregnant controls. Pregnancy Hypertension 6(4): 380-383.

32. Zunker P, Happe S, Georgiadis A, Louwen F, Georgiadis D, et al. (2000) Maternal cerebral hemodynamics in pregnancy-related hypertension. A prospective transcranial Doppler study. Ultrasound Obstet Gynecol 16(2): 179-187.

33. Schoknecht K, David Y, Heineman U (2015) The blood-brain barrier the gatekeeper to neuronal homeostasis: clinical implications in the setting of stroke. Semin Cell Dev Biol 38: 35-42.

34. Amburgey O, Chapman A, May V, Bernstein I, Cipolla M, et al. (2010) Plasma from preeclamptic women increases blood-brain barrier permeability. Hypertension 56(5): 1003-1008.

35. Wallace K, Tremble S, Owens M, Morris R, Cipolla M, et al. (2015) Plasma from patients with HELLP Syndrome Increases Blood-brain barrier permeability. Reprod Sci 22(3): 278-284.

36. Pampus VM, Wolf H, Mayruhu G, Treffers P, Bleker O, et al. (2001) Long-term follow-up in patients with a history of (H)ELLP syndrome. Hypertensi Pregnancy 20(1): 15-23.

37. Hammer E, Cipolla M (2015) Cerebrovascular Dysfunction in Preeclamptic Pregnancies. Curr Hypertens Rep 17(8): 64.

38. Johnson A, Tremble S, Chan S, Moseley J, LaMarca B, et al. (2014) Magnesium sulfate treatment reverses seizure susceptibility and decreases neuroinflammation in a rat model of severe preeclampsia. PLos One 9(11): e113670.

39. Cipolla M, Pusic A, Grinberg Y, Chapman A, Poynter M, et al. (2012) Pregnant serum induces neuroinflammation and seizure activity via TNFalpha. Experimental Neurology 234(2): 398-404.

40. Johnson A, Hammers E, Sakkaki S, Tremble S, Holmes G, et al. (2017) Inhibition of blood-brain barrier efflux transporters promotes seizures in pregnant rats: Role of circulating factors. Brain, Behavior, and Immunity. 
41. Sokol L, Epperson C, Barber JP (2013) Preventing postpartum depression: a meta-analytic review. Clin Psychol Rev 33(8): 1205-1217.

42. Huang H, Coleman S, Bridge J, Yonkers K, Katon W, et al. (2014) A metaanalysis of the relationship between antidepressant use in pregnancy and the risk of preterm birth and low birth weight. Gen Hosp Psychiatry 36(1): 13-18.
43. Suri R, Lin A, Cohen L, Altshuler LL (2014) Acute and long-term behavioral outcome of infants and children exposed in utero to either maternal depression or antidepressants: A review of the literature. J Clin Psychiatry 75(10): e1142-e1152.

\section{Your next submission with Juniper Publishers will reach you the below assets}

- Quality Editorial service

- Swift Peer Review

- Reprints availability

- E-prints Service

- Manuscript Podcast for convenient understanding

- Global attainment for your research

- Manuscript accessibility in different formats

( Pdf, E-pub, Full Text, Audio)

- Unceasing customer service

Track the below URL for one-step submission

https://juniperpublishers.com/online-submission.php 